ISSN: 0213-2052 - eISSN: 2530-4100

DOI: http://dx.doi.org/10.14201/shha201836135163

\title{
IMPERIO ROMANO, GLOBALIDAD Y LOCALIDAD EN LA PERIÉGESIS DE PAUSANIAS ${ }^{1}$
}

\author{
Roman Empire, Globality and Locality in \\ Pausanias' Periegesis
}

\author{
Álvaro M. MORENO LEONI \\ Universidad Nacional de Córdoba/UNC-CONICET \\ moreno.leoni@gmail.com
}

Fecha de recepción: 13-3-2018; aceptación definitiva: 20-5-2018

BIBLD [0213-2052(2018)36;135-163]

RESUMEN: El siguiente artículo busca explorar la relación que existe entre globalidad y localidad en la Grecia del siglo II d. C. Se propone, para ello, una lectura crítica de las descripciones de Pausanias de sus visitas a tres ciudades griegas imperiales: Tegea, Patras y Corinto. Se considera que los tres ejemplos exhiben de forma particularmente clara un desacuerdo entre el helenismo del autor, que es el marco imaginario universalista a partir del cual lo local es visitado y conocido en la Periégesis, y las memorias, identidades y prácticas de culto, que aparentemente son particularidades de dichos espacios locales. Sin embargo, un análisis más profundo nos permite advertir que estos fenómenos aparentemente particulares son muestras bastante evidentes de que las localidades en las que se hallan insertos están atravesadas profundamente por el fenómeno global del

1. Una primera versión de este trabajo fue presentada como conferencia en el 2016 en la Universidad de San Pablo (Brasil). Agradezco a Breno Battistin Sebastini su invitación en aquella oportunidad, así como al público presente en aquella oportunidad por las sugerencias. 
imperio. Se busca aquí, entonces, mostrar cómo, aunque Pausanias quiera discursivamente borrar de su obra la realidad histórica imperial, esta realidad emerge en su texto de todos modos porque el imperio mismo se ha convertido en un espacio de intenso intercambio cultural entre tendencias globales y experiencias locales.

Palabras clave: Pausanias; Globalidad; Localidad; Imperio Romano.

ABSTRACT: The following paper seeks to explore the relationship between globality and locality in Greece in the second century AD. In order to achieve that it is proposed a critical reading of Pausanias' descriptions of his visits to three imperial Greek cities: Tegea, Patras, and Corinth. These three examples are considered as showing in a particularly clear way a disagreement between the author's Hellenism, which is the universalist imaginary framework from which the local is visited and known in the Perigesis, and the memories, identities, and cult practices, which apparently are particularities of those local places. However, a deeper analysis allows us to notice that apparently particular phenomena are quite evident signs that the localities in which they are inserted are deeply traversed by the global phenomenon of the empire. It is sought here, then, to show how, although Pausanias wants discursively to erase from his work the imperial historical reality, this reality emerges in any case in his text because the empire itself has become a space of intense cultural exchange between global tendencies and local experiences.

Keywords: Pausanias; Globality; Locality; Roman Empire.

Los campesinos participaban en la función con un interés vivísimo. Los pueblos, los ríos, los montes de que se hablaba, no quedaban lejos de allí. De modo que los conocían, eran tierras como la suya y lanzaban exclamaciones de aprobación al oír aquellos nombres. Los espíritus y los demonios que aparecen en la tragedia y se sienten detrás de las escenas eran los mismos que vivían en aquellas grutas y aquellas arcillas... En aquella función, una vez despojada la tragedia por los actores y por el público de todo el dannunzianismo, sólo quedaba un contenido en bruto y elemental, que los campesinos sentían como propio $^{2}$.

Las miradas de los autóctonos y de los visitantes rara vez coinciden en sus percepciones cuando se posan sobre realidades locales. Mientras

2. Levi, C.: Cristo se detuvo en Éboli. Madrid, 2010 (1936), pp. 213-214. 
que entre los segundos, durante un viaje, suele prevalecer una evaluación estética, en el caso de los primeros, en cambio, la actitud a menudo es más compleja y se manifiesta mediante la expresión de determinadas conductas, el mantenimiento de tradiciones y la apelación a folclore, o, también, el recitado de mitos locales ${ }^{3}$. Carlo Levi expresa, a propósito de la representación en "Gagliano" (Aliano) de La verdad oculta de Gabriele D'Annunzio, la forma en que un discurso externo podía ser reapropiado y resignificado en clave local por un grupo de campesinos. Venido del norte, y confinado por el régimen fascista en la región de Lucania (Basilicata), entre los años 1935-1936, Levi entró en contacto con aquel otro mundo, al cual caracterizó como "negado a la Historia y al Estado y eternamente paciente", cerrado en sí mismo, profundamente "local".

Pero las condiciones del aislamiento material e imaginario de los campesinos del Mezzogiorno en las primeras décadas del siglo xx fueron quizá exageradas por Levi. El Estado italiano estaba, en efecto, bastante presente en aquella región a primera vista aislada. Los impuestos abusivos sobre la propiedad de las cabras, la conscripción militar con rumbo a Abisinia o el gigantesco urinal marmóreo ubicado en la plaza central del pueblo, cuya utilidad específica los lugareños parecían ignorar, volvían difícil olvidar el vínculo estrecho que había con Roma. También el contacto de la región con un mundo más amplio había sido mediado dos décadas atrás por las cadenas migratorias de cientos de jóvenes lucanos que se dirigieron a Estados Unidos o a Argentina, luego de la Primera Guerra Mundial: "El mundo exterior, por lo tanto, ha afectado bastante más de lo que inicialmente se nos permitió suponer ${ }^{4}$. Incluso, en nuestro epígrafe, la obra de D'Annunzio es reapropiada en términos locales por los campesinos, que hacen propios rasgos de una obra que abordaba una temática más universal. Podría sugerirse que, en su representación, ocurrió una "glocalización", es decir, una "particularización de lo universal y la universalización de lo particular", que en las últimas dos décadas se ha presentado como una perspectiva teórica capaz de captar mejor las implicancias de las complejas interacciones culturales entre globalidad y localidad en espacios locales concretos 5 .

3. Tuan, Y. F.: Topofilia. Un estudio de las actitudes, percepciones y valores sobre el entorno. Barcelona, 2007 (1974), pp. 92-93.

4. Horden, P. y Purcell, N.: The Corrupting Sea. A Study of Mediterranean History. Oxford, 2000, pp. 467-469.

5. Robertson, R.: Globalization. Social Theory and Global Culture. London, 1992, pp. $97-114$ 
En consonancia con estos desarrollos teóricos, el objetivo del presente trabajo es abordar la obra del viajero Pausanias atendiendo a la tensión experimentada en su Periégesis entre la dimensión local/peculiar de diversas costumbres descriptas en regiones griegas particulares y su lectura a partir de un marco cultural global de referencia del helenismo ${ }^{6}$. La idea de glocalidad puede permitir, desde nuestra perspectiva, superar un debate estéril entre localismo o panhelenismo en la obra de Pausanias, puesto que su texto, lejos de hacernos centrar la mirada en esta dicotomía, nos invita a entender, por el contrario, la articulación entre estas dos dimensiones como resultado de la inserción de Grecia en el espacio dinámico de intercambio y tensión cultural del imperio romano 7 . Para ello, proponemos estudiar los casos específicos de las visitas a Tegea, Patras y Corinto, que consideramos que constituyen puertas de entrada adecuadas para comprender la naturaleza compleja de las intersecciones de fenómenos globales del siglo II d. C., como el imperio romano y el helenismo, en espacios específicos de desarrollo de identidades, de rituales y de historia 'locales's.

Como intelectual, el periegeta no era ajeno al vasto proyecto de autoexamen cultural emprendido por la élite griega desde mediados del siglo I d. C. Sin embargo, sus preocupaciones oscilaban de forma bastante errática entre un interés por seleccionar y recuperar "todas las cosas

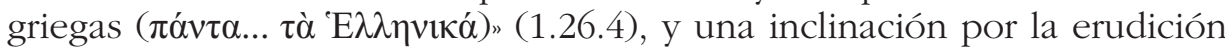

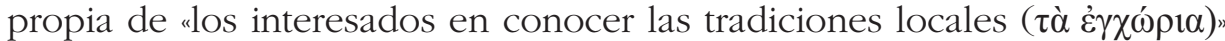
$(1.1 .4)^{9}$. Con todo, su marco interpretativo del helenismo, que actúa como una regla estándar laxa para evaluar las experiencias locales, resulta a

6. Adopto una perspectiva laxa de "helenismo", que es también dinámica y flexible, nunca taxativamente definida y que podría entenderse concretamente durante el imperio romano como un "lenguaje, pensamiento, mitología e imágenes que constituían un medio extraordinariamente flexible tanto de expresión cultural como religiosan: BowERSOCK, G.: Hellenism in Late Antiquity. Cambridge, 1990, p. 7.

7. Tomo la idea de "tensión dinámica" como estructuradora del contacto cultural en el Mediterráneo oriental de: Woolf, G.: "Becoming Roman, staying Greek: Culture, identity and the civilizing process in the Roman East", PCPhS, 40, 1994, p. 135.

8. Rescato la idea de MuñIz Grijalvo de que, si bien Pausanias se centra imaginariamente en el mundo griego, su obra es impensable sin el marco del imperio: "La versión griega de la religión cívica como factor de integración en la ecúmene romana", SHHA, 26, 2008, pp. 127-128.

9. Esto último sugerido por: Jost, M.: "Unité et diversité: la Grèce de Pausanias", REG, 119, 2006, p. 574. Se ha utilizado la edición de Musti, Maddoli y Moggi: Pausania. Guida della Grecia, libros I-X. Milano, 1982-2012; y la traducción de Herrero Ingelmo, con ligeras modificaciones: Pausanias. Descripción de Grecia, libros I-X, vol. I-III. Madrid, 1993. Los pasajes citados sin indicación de autor pertenecen siempre a Pausanias. 
la vez absolutamente coherente con esta preocupación por lo local, al menos, en dos niveles.

Desde el punto de vista de la tradición literaria, por un lado, Pausanias se erige como un imitador consciente del modelo de Heródoto, reproduciendo su estilo narrativo y su modo de argumentación. Esto se observa, quizá de forma más notable, en su afirmación de que "la mayor parte de los asuntos de Grecia son objeto de disputa (

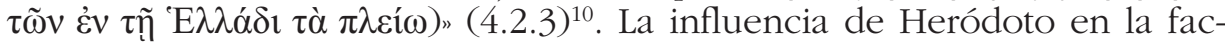
tura de su relato es incluso más profunda, puesto que, de acuerdo con Luraghi, uno de los rasgos centrales de la obra del historiador jonio era su sensibilidad por la cuestión de la distribución local del conocimiento en Grecia. Objetos específicos, depositados en santuarios locales, pero también panhelénicos que, de acuerdo con la iconotropía de J. Vasina, actuaban como vehículos para las percepciones del pasado compartidas imaginariamente por las comunidades locales ${ }^{11}$.

Existen ciertamente reparos en identificar estrictamente la naturaleza "local" de la información con los supuestos puntos de vista "reales" de informantes puntuales, en la medida en que, tanto Heródoto como Pausanias, podían recurrir a estas opiniones como un modo de crear con su relato la ficción de un contacto con comunidades homogéneas que expresaban tradiciones ${ }^{12}$. Sin embargo, puede argumentarse también que, cuando Pausanias se refiere a los testimonios orales "colectivos" de los locales (atenienses, corintios, etc.), y como observó H. Erbse sobre el doble significado en prosa del verbo $\lambda \dot{\gamma} \gamma \omega$ como "decir, afirmar" y como "creer, pensar", exhibe cierta inclinación por presentar a sus lectores una preocupación por el conocimiento colectivo local ${ }^{13}$.

Por otro lado, en la última década, los estudios sobre globalización en el mundo antiguo en general, y sobre el fenómeno en el imperio romano en particular, han hecho avances significativos que han redundado en una mejor comprensión de la interconexión e integración de los fenómenos mediterráneos a escala local. J. Jennings, en ese sentido, ha

10. $4.4 .3 ; 6.20 .18 ; 2.12 .3$; 3.11.5-6; 8.53.5; 9.16.7; 31.6; etc. La imitación de Heródoto es reconocida hace tiempo: Dorati, M.: "Pausania e il modello erodoteo: le tradizioni di Fliunte", en Giangiulio, M. (ed.): Erodoto e il 'modello erodoteo'. Formazione e trasmissione delle tradizioni storiche in Grecia. Trento, 2005, pp. 315-348. Un tipo de razonamiento que se remonta, en mi opinión, al prefacio de las Genealogias de Hecateo: FGrHist 1, F1.

11. Luraghi, N.: "Local Knowledge in Herodotus' Histories", en Luraghi, N. (ed.): The Historian's Craft in the Age of Herodotus. Oxford, 2007 (2001), pp. 148-149.

12. Giangiulio, M.: "Constructing the Past: Colonial Traditions and the Writing of History: The Case of Cyrene", en N. LuRAGHI: 2007, 137.

13. ERBSE, H.: Studien zum Verständnis Herodots. Berlin-New York, 1992. 
individualizado en su estudio comparativo ocho indicadores de globalidad compartidos por algunas sociedades antiguas. Allí, junto con factores que suponen una compresión tiempo-espacio, y que implican cierta estandarización de la cultura material, ha advertido la ocurrencia de fenómenos aparentemente contrarios. Paralelas a la globalización pueden advertirse, en ese sentido, tendencias al reforzamiento de la heterogeneidad cultural y de fortalecimiento de unas fronteras que la globalidad está difuminando, una re-incrustación de la cultura local y una sensación de vulnerabilidad ante el cambio global ${ }^{14}$. Esto revelaría en diversos ámbitos espaciales e históricos una coexistencia entre tendencias globales y localidad, como ocurre en el Mediterráneo en el siglo il d. C. cuando se asiste a la fase final de un largo proceso cultural caracterizado por la universalización de elementos pertenecientes a una cultura específica del Mediterráneo y, por el otro, de particularización de los mismos en cada uno de los diversos contextos locales ${ }^{15}$. Pienso que Pausanias, como viajero griego de la élite educada helenizada (pepaideuménos), tanto por el modelo narrativo adoptado, como por su procedencia social, poseía cierta sensibilidad para captar este tipo de problemas globales del helenismo y del imperio romano. Estaba en buena posición, en efecto, para advertir los matices de las manifestaciones locales de una cultura griega que sabía que no era monolítica, ni podía serlo, sino que estaba compuesta por un mosaico de

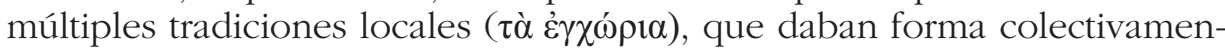
te, en su diversidad, a lo que él llamaba "todas las cosas griegas" ( $\pi \alpha ́ v \tau \alpha . .$. $\tau$ à $\left.{ }^{\mathrm{E}} \lambda \lambda \eta \nu \imath \kappa \alpha ́\right)$.

El abordaje del problema de la intersección entre lo global y lo local en la Periégesis puede permitir avanzar en la comprensión de las apuestas culturales en el contexto del dominio romano sobre el mundo griego. Además, este estudio puede contribuir a superar cierto estancamiento del debate historiográfico específico entre quienes consideran que Pausanias tenía un proyecto cultural orientado a construir una memoria y una identidad panhelénicas y quienes, por su parte, creen que estaba preocupado exclusivamente por recolectar tradiciones e historias curiosas para entretener e informar a sus lectores ${ }^{16}$. Desde la perspectiva que abordaremos el problema, no tendríamos que ver ambas actitudes como modalidades excluyentes, puesto que el texto provee los indicios necesarios para acceder

14. Jennings, J.: Globalizations and the Ancient World. Cambridge, 2011, pp. 121-142.

15. Versluys, M.: "Roman Visual Material Culture as Globalising Koine», en PitTs, M. y Versluys, M. (eds.): Globalisation and the Roman World. World History, Connectivity and Material Culture. Cambridge, 2015, p. 155.

16. Remito a una breve discusión en Jost: 2006, 569-571. 
al diálogo implícito entre lo global y lo local en su obra y en su contexto histórico.

Sobre el autor y su obra, puede decirse que existe cierto acuerdo en que los diez libros de su Periégesis, Recorrido, Descripción o Guía de Grecia, fueron escritos entre ca. 155-175 d. C. Del autor, nada sabemos más allá de las propias referencias internas en la obra, lo que supone un estricto filtro narrativo ${ }^{17}$. Se supone que su lugar de origen puede haberse situado en Asia Menor, posiblemente en Magnesia del Sípilo en Lidia $(5.13 .7)^{18}$. La mayor parte de la información que le permitió componer su obra la habría, por su parte, recolectado durante sus viajes, que pudieron ser más de uno, y que asoció a su escritura dando un apropiado comienzo in medias res a su escrito: "Delante del continente griego en dirección a las islas Cícladas y al mar Egeo se extiende Sunio, promontorio del Ática" (1.1.1). Esto situaba al lector en la perspectiva de alguien que se aproximaba en barco a Grecia desde el Este para iniciar un recorrido junto al autor ${ }^{19}$. En cierta forma, reproduciría así su propia llegada desde Asia Menor al continente, y también imitaría los vínculos de visibilidad egeos entre islas y líneas $\operatorname{costeras}^{20}$. Es un viajero forastero, por lo tanto, e invita al lector a compartir su viaje para formarse.

Pausanias conoció personalmente buena parte de Grecia continental, aunque no de forma completa, y propuso a sus lectores un recorrido bastante fiable por lugares y monumentos arcaicos, clásicos y helenísticos que todavía eran visibles en el paisaje de su época. Los theorémata, o "cosas para ver", constituían esta dimensión descriptiva del texto, que contextualizó e ilustró con extensas digresiones, o lógoi, "discursos", de tipo histórico, mítico y religioso (1.39.3) ${ }^{21}$. Al respecto, puede señalarse que esto podía estar vinculado con la necesidad de complementar la percepción puramente estética ofrecida al lector como visitante imaginario, y forastero, que requiere para obtener una experiencia más significativa y menos efímera cierta consciencia del pasado para fijar la atención más

17. AkuJÄRVI, J.: Researcher, Traveller, Narrator: Studies in Pausanias' Periegesis. Lund, 2005, pp. 54-55.

18. Haвicht, Ch.: Pausanias' Guide to Ancient Greece. Berkeley, 1985, pp. 10-15. Sobre su identidad lidia: Jones, Ch.: "Multiple Identities in the Age of the Second Sophistic", en Borg, B. E. (ed.): Paideia: The World of the Second Sophistic. Berlin, 2004, pp. 13-21.

19. Hutton, W.: Describing Greece. Landscape and Literature in the Periegesis of Pausanias. Cambridge, 2005, p. 13.

20. Sobre el problema de los vínculos de visibilidad en paisajes de conectividad entre microrregiones: Horden y Purcell: 2000, 128-130.

21. Robert, C.: Pausanias als Schriftsteller. Studien und Beobachtungen. Berlin, 1909, pp. 3-7, 8-68. 
detenidamente sobre determinados rasgos del paisaje o de una obra de $a_{r t e}^{22}$. Para lograr este efecto, el periegeta efectuó una selección propia de tradiciones (orales y escritas), de obras y de acciones históricas de

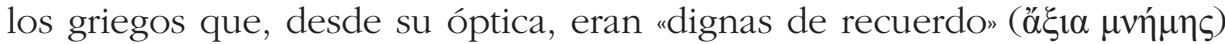
porque dotaban de sentido a cada uno de los lugares y objetos descriptos en la obra. La actitud de la historiografía frente a estos lógoi de la obra, en ese sentido, ha cambiado en los últimos treinta años ${ }^{23}$. Su integración ya no se interpreta como una compilación "objetiva" de información para los viajeros, sino como parte orgánica de un marco interpretativo propio ${ }^{24}$.

Sus fuentes eran variadas. Por un lado, compartía una formación intelectual común con las élites helenizadas. A esto se sumaba su conocimiento de primera mano de los principales sitios en Grecia. Si bien sus lecturas no eran profundas, su conocimiento era vasto en religión, arte e historia griegas. Por otro lado, su información también era de carácter local/oral, recogida mediante entrevista, pero también observación y lectura de epígrafes in situ. En cualquier caso, su rasgo más notable es la persistente definición de sus interlocutores como "locales", que exponen al autor sus propias tradiciones. Pausanias utiliza, en efecto, el término

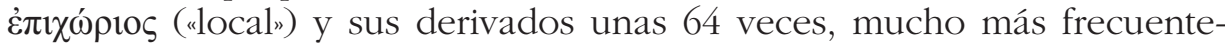
mente que cualquier otro autor griego ${ }^{25}$. Estas tradiciones podrían bien ser vehículos para el acceso a memorias e identidades "locales" polifónicas, que Pausanias consideraba colectivas, distintas y objeto de disputa. Su preocupación por la aprehensión del pasado en clave "local", que permitía presentar a Grecia al mismo tiempo como una y como múltiple, vuelve significativa nuestra indagación sobre sus visitas a Tegea, Corinto y Patras. Las mismas constituyen puertas de entrada para el abordaje de la paradoja de la coexistencia de un mundo griego global y un espacio local incrustado en el imperio romano.

\section{El santuario de Alea Atenea en Tegea (Arcadia)}

En su recorrido por Arcadia, Pausanias arriba desde Megalópolis al templo de Alea Atenea en el territorio de Tegea (8.45.4-7). Aquel era un santuario extraurbano importante emplazado en el demo de Afidas, que

22. TuAn: $2007,130-131$.

23. Es seminal el estudio de Habicht: 1985.

24. HutTon: 2005, 4.

25. Goldhill, S.: "What is local identity? The politics of cultural mapping?", en Whitmarsh, T. (ed.): Local Knowledge and Microidentities in the Imperial Greek World. Cambridge, 2010, pp. 46-68. 
había sido calificado previamente en la obra como "venerado desde antiguo por todos los peloponesios" $(3.5 .3 ; 6)^{26}$. Su origen era anterior al sinecismo de Tegea como pólis, un acontecimiento del $\mathrm{v}$ a. C., y es posible que datara de los siglos IX-VIII a. C. ${ }^{27}$. La diosa Alea, tardíamente asociada con Atenea, por su parte, era una diosa local arcaica que preservó su entidad propia sin jamás llegar a ser reducida a una epíclesis ${ }^{28}$. La importancia de su culto en el área se prolonga en el tiempo desde época arcaica hasta el dominio romano, puesto que se sabe, por ejemplo, que Estrabón (8.8.2) advirtió en su Geografía que tanto el templo como la ciudad eran relativamente prósperas en su época pese a la dureza de la situación general del continente griego que el geógrafo creía advertir.

En 8.46.1, a propósito de las ofrendas depositadas en el santuario, Pausanias menciona que Augusto habría tomado del templo una imagen antigua ebúrnea de la diosa, obra del escultor Endoio del siglo vi a. C., y que también se habría llevado los colmillos del jabalí de Calidón como castigo a los tegeatas por su alianza con M. Antonio en Accio. Con respecto a las demás ofrendas, añade la siguiente información:

(2) En cuanto a ofrendas en el templo, las más dignas de mención son: la piel del jabalí de Calidón completamente podrida por el tiempo y totalmente pelada. Están colgados los grilletes llevados por los prisioneros lacedemonios cuando cavaban la llanura de los tegeatas, excepto los que ha carcomido la herrumbre. Están dedicados un lecho sagrado de Atenea, un retrato pintado de Auge y el escudo de Quera, una mujer de Tegea, de sobrenombre Marpesa. De ésta haremos después mención. (8.47.2).

Es particularmente notable la exposición de los grilletes de los prisioneros espartanos (junto con el escudo de Quera, cf. 8.48.5). Supuestamente, se trataba de objetos de gran antigüedad, relacionados con la invasión espartana de Carilo en época arcaica $(3.2 .5 ; 7.3 ; 8.48 .4-$ 6), a la que Pausanias alude siguiendo de cerca el relato de Heródoto $(1.66)^{29}$. Se trata, en efecto, de ofrendas particularmente apropiadas para

26. Aunque la denominación escogida por Pausanias, Atenea Alea, o simplemente Atenea (8.47.2-4), traiciona el marco cultural global desde el cual el periegeta aprehende este culto local. No hay signos de participación extra arcadia en el culto, o en los juegos asociados, hasta antes del siglo III a. C. En el siglo II a. C. la ciudad de Epidauro celebra a un tal Sócrates por vencer en las Aleaia (IG IV 2 1.629, 1. 6).

27. Jost, M.: Sanctuaires et cultes d'Arcadie. Paris, 1985, pp. 143, 146.

28. Jost: $1985,369$.

29. Sobre la cronología: ImmerwaHr, W.: Die Lakonika des Pausanias auf ibre Quellen untersucht. Berlin, 1889, p. 34; MeADows, A.: "Pausanias and the Classical Historiography of Classical Sparta", CQ, 45 (1), 1995, pp. 97-98. 
la diosa, puesto que su santuario parece haber estado relacionado con el asilo y con el mantenimiento a distancia de los enemigos ${ }^{30}$. Según M. Jost: "Alea Atenea fue concebida como una diosa marcial armada con la égida, el casco, la lanza y el escudon" ${ }^{31}$.

Podría considerarse entonces que los objetos observados por el periegeta en su época operaban como vectores materiales que mediaban en la orientación de la comunidad hacia su pasado. En ese sentido, estos objetos soportaban sobre ellos trabajos específicos de memoria local y se convertían, de ese modo, en los signos visibles de una variopinta distribución local de percepciones sobre el pasado en el paisaje griego imperial. No creo, por otra parte, que estos objetos necesiten ser considerados como exhibiciones asépticas de "tradiciones conservadas", de vestigios cuidados de un pasado rescatado, idea sobre la que sin duda subyace el trillado argumento romántico de la inmanencia de las identidades y de las memorias locales. En cambio, estos objetos, y las narrativas asociadas a ellos, deberían entenderse más bien como productos significantes para la comunidad tegeata contemporánea ${ }^{32}$. Así, el foco del estudio podría desplazarse del interés anticuario por los vestigios hacia una indagación sobre la relevancia socio-cultural del vínculo que toda comunidad tejía permanentemente con su historia, puesto que le proporcionaba un fundamento y una percepción de su lugar en el presente.

Al respecto, M. Pretzler reconoció, en efecto, que existía una divergencia entre el relato existente en la historiografía clásica y esta historia local a propósito justamente de estas ofrendas ${ }^{33}$. Si bien en su relato de la historia tegeata el periegeta no parece apartarse demasiado de lo conocido por otras fuentes literarias con respecto al rol de los tegeatas como leales aliados de los espartanos en Platea (Hdt. 9.56; 60.2; 70), respecto a las ofrendas dedicadas ( $\alpha v \alpha \theta \eta \dot{\mu} \mu \alpha \tau \ldots . . \mu v \eta \dot{\mu} \mu \nu)$, en cambio, menciona solo la existencia de los grilletes (cfr. Hdt. 1.66; 9.70). Pero al hacerlo, evidencia

30. Fougères, G.: Mantinée et l'Arcadie orientale. Paris, 1898, p. 290.

31. Jost: 1985, 379. Ver: E., Fr. 266 NAUCK$^{2}$.

32. Sobre este problema de las memorias locales y las comunidades, ver: RuFER, M.: "Paisaje, ruina y nación. Memoria local e historia nacional desde narrativas comunitarias en Coahuila", Cuiculco, 21 (61), 2015, pp. 103-136. En el Peloponeso de los primeros dos siglos del imperio las élites y el emperador se convirtieron en actores centrales que pusieron en juego en templos específicos estrategias de intervención que dispararon nuevos significantes para la memoria y la identidad locales de las comunidades. Cfr. Gengler, O.: "De qui est la mémoire? Construction identitaire et image du passé dans les sanctuaires du sud du Péloponnèse sous le haut-empire", en Gangloff, A. (ed.): Lieux de mémoire en Orient grec à l'époque impériale. Berna, 2013, pp. 179-198.

33. Pretzler, M.: Pausanias: Travel Writing in Ancient Greece. London, 2007. 
una importante omisión con respecto al relato herodoteo: los restos del pesebre de bronce de Mardonio, tomado como botín por los tegeatas (Hdt. 9.70.3).

El templo antiguo sufrió un incendio en el 395/4 a. C. (tal como es afirmado en 8.45.4) y, por ello, la pregunta inevitable que asalta al lector es si los grilletes pudieron salvarse en aquella oportunidad del fuego. Es posible, puesto que eran de hierro, pero parece dudoso. En efecto, el mismo argumento de la preservación material podría utilizarse con respecto al pesebre de Mardonio, que parece, en cambio, esfumarse por completo del registro. La interpretación más probable, en efecto, es que los grilletes fueron repuestos, en algún momento, y de acuerdo con objetivos y perspectivas específicas, tras la reconstrucción del templo a mediados del siglo IV a. C. ${ }^{34}$. Este acto de conmemoración podría permitirnos reconocer, en ese sentido, un aspecto de cómo la comunidad cívica de los tegeatas escogió tras su ruptura con la Liga del Peloponeso representarse colectivamente ante el conjunto de los visitantes del santuario. La imagen proyectada sería, pues, la de enemigos implacables, y vencedores por las armas, de sus "invictos" vecinos sureños, dilatando luego esta memoria una vez incorporada Tegea al dominio romano.

De acuerdo con un procedimiento común en su obra, Pausanias introducía su relato sobre los tegeatas indicando, en efecto, su participación en gestas comunes arcadias (en Ilión, las Guerras Médicas y Dipea contra los espartanos) y también en acciones individuales (como la caza del jabalí de Calidón, el rechazo de los Heráclidas). Entre estas últimas, destacaba el haber sido "los primeros arcadios que vencieron a los lacedemonios cuando les atacaron y cogieron prisioneros a la mayoría de ellos" (8.45.2$3)$. En ese sentido, en el relato de Diodoro, que puede estar elaborando a partir de la obra de Éforo del siglo IV a. C., al producirse el primer retorno de los Heráclidas, Hilo, el hijo de Heracles y, por ende, antepasado mítico de los reyes espartanos, resulta muerto en combate singular justamente por Équemo, rey de Tegea (Diod. 4.58.1-5; Paus. 1.44.10) ${ }^{35}$. Según Heródoto (9.71.1), los tegeatas se habían destacado en Platea, junto con los espartanos y atenienses, aunque no menciona su participación en la batalla como aliados de Esparta. Sí llama la atención, en cambio, sobre la

34. PRETZler: 2007, 97-100.

35. Hall, J.: Hellenicity. Between Ethnicity and Culture. Chicago, 2005 (2002), p. 74; Pero Diodoro no es un copista lineal, ni carece de objetivos propios: SACKs, K.: Diodorus Siculus and the First Century. Princeton, 1990; Vega Rodríguez, H. A.: La Biblioteca Histórica de Diodoro de Sicilia. Universalidad, escritura de la historia y el retrato de los cartagineses. Trabajo Final de Máster, Máster del Mediterráneo Antiguo UOC-UAB-UAH, Barcelona, 2017, pp. 40-47. 
batalla contra Carilo, que dará lugar a la importante ofrenda de los grilletes en el santuario de Alea Atenea ${ }^{36}$.

Pueden advertirse, además, algunos indicios de la perspectiva local tegeata en el relato de Pausanias, que, en este caso, echan luz sobre la memoria y el sentido local del pasado. Tras introducir las acciones tegeatas en la historia griega, el periegeta guarda silencio notablemente sobre la participación de aquellos en Platea (cfr. 9.2.5), y el lector, en cambio, se topa con reiteradas menciones a los combates victoriosos de los tegeatas contra los espartanos (3.7.3; 8.45.3; 48.4-5; 53.9-10; 9.9.6; etc.). Sin embargo, no hay una sola indicación de la histórica alianza que vinculó a Tegea con Esparta entre los siglos VI-IV a. C. La síntesis histórica de Pausanias coincidiría, por lo tanto, con lo expuesto por los propios tegeatas en el templo de Alea Atenea, en tanto que estos vectores materiales (los grilletes) proponían una lectura de la experiencia pasada que apuntalaba una imagen presente de superioridad. El heroísmo de su victoria sobre los espartanos desplazaba en la operación contemporánea de memoria local a la participación "panhelénica" en las Guerras Médicas, lo que ocasionaba que la perspectiva 'local' tegeata entrara en tensión con otra perspectiva 'local', que había sido expuesta por el autor previamente. En efecto, los espartanos, según el periegeta, afirmaban por aquella época no haber sido derrotados por nadie seriamente antes de Leuctra (371 a. C.) (1.13.5).

Este último punto es importante dentro de las coordenadas político-culturales imperantes en Grecia tras la conquista romana. Mostrar públicamente, en aquella época, una imagen colectiva de vencedores en batalla sobre los espartanos podía constituir una fuente efectiva de orgullo y prestigio cívicos, que buscaba, por lo tanto, ser capitalizada por cualquier comunidad local, sobre todo, a partir del vigor alcanzado por el tópico de la virtus militar espartana. Los propios espartanos la celebraban, como ocurría, por ejemplo, durante el festival de la Leonidea (en honor de Leonidas y Pausanias), mencionado por Pausanias (3.14.1), uno de los juegos funerarios revitalizados tras Accio por la intervención del notable local C. Julio Euricles, el aliado de Octaviano. Pero también, en época imperial, como señala Spawforth, "en Roma la gente educada realmente

36. De difícil datación, es probable que no sea un acontecimiento del siglo vIII, sino de mediados del vi a. C. previo a la conformación de la Liga del Peloponeso: Fornis, C.: Esparta. La historia, el cosmos y la leyenda de los antiguos espartanos. Sevilla, 2016, pp. 37 , 87-88. Cfr. Con el argumento de Josef HejNIC, que consideraba a Carilo como un "personaje semi-mítico", y lo situaba posiblemente en el siglo viI a. C.: Pausanias the Perieget and the Archaic History of Arcadia. Praha, 1961, p. 83. 
veía arma como la provincia especial de los espartanos ${ }^{37}$. La sentencia de Cestio Pío al respecto es clara: "Cada Estado tiene su gloria peculiar. Atenas es famosa por la elocuencia, Tebas por la religión, Esparta por las armas" (Sen., Suas. 2.5). En este juego cultural cruzado, de aspiraciones griegas y expectativas romanas, las respuestas de las comunidades griegas que pretendian tener una historia que contar sobre sus guerras contra Esparta distaban de ser pasivas. Dion de Prusa señala, por ejemplo, que los atenienses de su época: "por monumento mejor y más excelente tienen la daga persa de Mardonio y los escudos de los espartanos capturados una vez en Pilos, que los Propileos de la Acrópolis y el Olimpeión, que costó más de diez mil talentos" (D. Chr. 2.36) ${ }^{38}$.

Los atenienses, por lo tanto, no se conformaban con quedar relegados a ocupar el terreno de la elocuencia, y esto repercutía en la memoria cívica. Pausanias (9.2.5) menciona, en efecto, la existencia en el lugar de memoria de Platea de tumbas diferenciadas de atenienses y espartanos. Allí, se organizaron en época romana juegos en los que, como en el uso tópico de la batalla en la oratoria imperial, se acentuaba el papel de Esparta y de Atenas y se dejaba de lado, por ejemplo, la intervención de los tegeatas ${ }^{39}$. A nivel local, en la Esparta romana se habría recreado para dar sustento al mito también la agogé de Licurgo y una serie de festivales que recordaban el rol central espartano en la derrota de los persas, llegando a ser explotado simbólicamente también, incluso, por los emperadores L. Vero (161), Caracalla (214) y, posiblemente, Juliano (363), que llegaron a solicitar contingentes espartanos para sus campañas contra partos y sasánidas ${ }^{40}$.

La historia reciente, percibida por los tegeatas, estaba marcada por una constante rivalidad con los vecinos del sur tras la salida de la Liga del Peloponeso, la batalla de Leuctra y la creación de la Confederación Arcadia (371/0 a. C.) $)^{41}$. En el siglo III a. C. los espartanos habían llegado incluso a conquistar Tegea, aunque pronto tuvieron que retirarse ante la

37. SpaWforth, A.: Greece and Augustan Cultural Revolution. Cambridge, 2012, pp. 124-127.

38. Aunque no recala específicamente en esta intencionalidad ateniense de recordar una victoria sobre Esparta, es de interés con respecto al problema de la historia intencional y las topografías de la memoria: ANTELA BERnárdez, B.: "El paisaje urbano de Atenas, entre memoria de guerra e identidad colectiva", en Vidal, J., ANTEla, B. y Sierra Martín, C. (eds.): Memoria del Conflicto en la Antigüedad. Zaragoza, 2017.

39. SPAWFORTH: 2012, 136.

40. Cartledge, P. y Spawforth, A.: Hellenistic and Roman Sparta: A Tale of Two Cities: London, 2002, pp. 176-195.

41. Cartledge y Spawforth: 2002, 2-3. 
llegada de Filopemén (207 a. C.) (8.52.6; Pol. 9.18.7-8). Finalmente, en el siglo I a. C., esta rivalidad con los espartanos tuvo su punto cúlmine cuando Tegea, junto con el resto de Arcadia excepto Antigonea (Mantinea), decidió seguir a M. Antonio en Accio debido a su odio hacia Esparta $(8.8 .12)^{42}$. A pesar de la derrota final, y de la humillación a manos de Augusto, la propia percepción de un pasado de virtus militar equiparable a la de los espartanos, enaltecidos ahora por el emperador, siguió siendo vehiculizada a través de estos grilletes que dieron soporte material a la circulación de historias asociadas con el primer intento de invasión de los espartanos a Tegea, "que era el lugar más fortificado y más importante de Arcadia" y fueron derrotados por sus valerosos ciudadanos ${ }^{43}$.

La percepción 'local' del pasado en Tegea muestra, por lo tanto, una toma de posición frente a un verdadero tópico cultural sobre el valor marcial de los espartanos en el imperio romano. Pese a su virtus militar, apuntalada desde la ideología imperial augustea como un modo de integrar simbólicamente al mundo griego dentro de las nuevas coordenadas morales e históricas del principado, y celebrada localmente en Esparta durante los primeros siglos del imperio, habían sido superados militarmente por los tegeatas, que podían exhibir con orgullo esta hazaña pasada de haber dominado y esclavizado a los campeones de Grecia. Todo viajero suficientemente curioso, como Pausanias lo era, podía hallar la prueba de este valor pretérito en un par de grilletes oxidados ofrendados en un templo abierto a todos los peloponesios.

\section{El sacrificio a Ártemis lafria en Patras}

En su visita a Patras, en el libro VII, Pausanias tenía la posibilidad de abordar varios cultos, algunos recientemente introducidos, pero se mantuvo apegado a lo que podría denominarse cultos "tradicionales" " ${ }^{44}$. Ya hemos advertido la sospecha de inmanentismo romántico que pesa sobre este tipo de supervivencias culturales pretéritas. En ese sentido, describe de forma bastante detallada un peculiar sacrificio en honor de Ártemis Lafria:

42. Sobre la participación de Mantinea y la instauración del culto de Afrodita Symmachía para celebrar Accio y su alianza con Roma: Tsiolis, V.: "Santuarios de Arcadia y dominio romano", en Cortés Copete, J. M., Muñiz Grijalvo, E. y Gordillo Hervás, R. (coords.): Grecia ante los imperios, V Reunión de historiadores del mundo griego. Sevilla, 2011, pp. 277-278.

43. D. Chr. 17.16.

44. Rizakis, A.: Achaïe II. La cité de Patras. Épigraphie et histoire. A日ńva, 1998, p. 35. 
Los de Patras celebran una fiesta de Lafria en honor de Ártemis todos los años en la que emplean una forma de sacrificio peculiar del

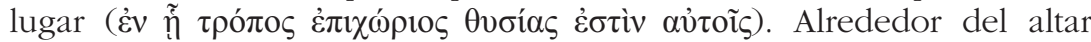
colocan en círculos leños todavía verdes, cada uno de hasta dieciséis codos. Dentro, sobre el altar están los leños más secos. Con ocasión de la fiesta preparan una subida al altar más suave echando tierra encima de sus escalones. En primer lugar, hacen una magnífica procesión en honor de Ártemis, y la doncella que sirve de sacerdotisa va la última en la procesión sobre un carro tirado por ciervos uncidos. Al día siguiente ya acostumbran a celebrar el sacrificio y la ciudad públicamente y no menos los particulares se afanan en esta fiesta. En efecto, echan sobre el altar aves vivas comestibles y todo tipo de víctimas igualmente, y además jabalíes, ciervos y gacelas, y algunos echan lobeznos y oseznos y otros animales ya crecidos. Depositan también sobre el altar frutos de árboles cultivados, y después de esto prenden fuego a los leños. Entonces vi un oso y otros animales presionando con fuerza hacia afuera bajo el primer ataque del fuego, otros que se escapaban gracias a su fuerza; pero los que habían echado los llevaban de nuevo a la pira, y no recuerdan que nadie fuera herido por los animales. (7.18.11-13).

Se advierte desde un primer momento este sacrificio como extraño, anómalo, con respecto a la práctica griega. Como señala V. PirenneDelforge, cuya argumentación se sigue aquí, algunos elementos son notables: se quema a los animales sin ser previamente sacrificados, no se solicita su consentimiento y, sobre todo, se utiliza indistintamente cualquier animal, incluso, aquellos especialmente salvajes ${ }^{45}$. W. Burkert, por su parte, menciona este pasaje en su magna obra como un ejemplo conspicuo del "sacrificio de fuego", quizá de forma imprecisa, pero, sin embargo, también escribía al pasar, a propósito de la visualidad y características de este sacrificio, que durante su realización "el santuario se vuelve un anfiteatro" ${ }^{46}$. No prosigue con este argumento, pero, en efecto, el lector puede vincular la descripción del sacrificio con el hecho de ser realizado en una colonia romana.

La Colonia Augusta Achaica Patrensis ${ }^{47}$, fundada en algún momento entre el viaje por Oriente del princeps (23/21 a. C.) y el de Agripa (16/14 a. C.), quizá en dos etapas, con la instalación inicial de veteranos de las legiones XII Fulminata y X Equestris de M. Antonio (Str. 8.7.5 = C387),

45. Pirenne-Delforge, V.: "Ritual Dynamics in Pausanias: The Laphria", Kernos, suppl. 16, 2006, pp. 123-124.

46. BurKert, W.: Greek Religion. Cambridge (Ma.), 1985, pp. 62-63.

47. La lectura numismática del desarrollo de CAAP: Agallopou, P.: "Two unpublished Coins from Patrae and the Name of the Roman Colony", Hesperia, 18 (4), 1989, pp. 445447; RIZAKIS: 1998, 21. 
primero, y luego un segundo poblamiento con Agripa ${ }^{48}$. Junto con las fundaciones de Nicópolis en Epiro, Pella y Dio en Macedonia, formó parte de un "vasto plan de reacomodamiento del espacio político de la península griega ${ }^{49}$. Pausanias (7.18.7; 22.1, 6; 8.27.1; cfr. Str. 10.2.21), en efecto, muestra que su establecimiento implicó una vasta reestructuración y ampliación del territorio políada original, que motivó que grandes franjas de territorio a ambos lados del golfo de Corinto pasaran a integrar las tierras de la ciudad ${ }^{50}$.

El periegeta advierte a sus lectores, en relación con esta cuestión, que este culto había sido importado desde el otro lado del golfo y que su performance en Patras, en efecto, era el resultado específico de la intervención romana en el espacio griego: Es una diosa con nombre «extranjero", con una imagen "traída de otro lugar", es decir, de Calidón en Etolia, que fue despoblada para fundar Nicópolis y desposeída de esta diosa que fue entregada por el emperador a Patras (7.18.8-9). Pero después de realizar estas afirmaciones, señala sin titubear que la forma de sacrificio era

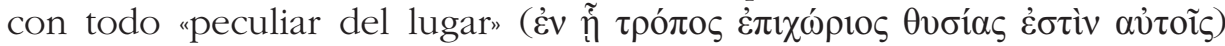
(7.18.11).

El origen de este extraño sacrificio epichórios, y su sentido, ha sido muy debatido y se han propuesto varias hipótesis ${ }^{51}$. Según PirenneDelforge, en la idea esbozada por Burkert de un santuario convertido en un anfiteatro puede residir la clave. La dimensión espectacular, en efecto, ha sido atribuida a otros sacrificios rituales como el de Ártemis Ortia en Esparta, que con su espectáculo de sangre y su pretendido pedigrí arcai$\mathrm{co}$, ha sido caracterizado como una reinvención apropiada para el gusto cultural y turístico romano de los primeros siglos del imperio ${ }^{52}$. Por lo tanto, dice Pirenne-Delforge: "La explicación más simple y apropiada ve en este ritual una reconstrucción augustea, perfectamente digna de DianaÁrtemis, la diosa cazadora, tanto para griegos como para romanos. Estaba perfectamente en concordancia con los espectáculos romanos violentos y con el gusto por la presumida antigüedad, ${ }^{53}$.

48. RIZAKIS: 1998, 24-28.

49. RIZAKIS: 1998, 27.

50. Alcock, S.: Graecia Capta. The Landscapes of Roman Greece. Cambridge, 1993, pp. 136-141.

51. Pirenne-Delforge: 2006, 118-122.

52. Otros cultos "reinventados": PIÉrART, M.: «Panthéon et hellénisation dans la colonie romaine de Corinth: la 'redécouverte' du culte de Palaimon à l'Isthme", Kernos, 11, 1998, pp. 85-109.

53. Pirenne-Delforge: 2006, 126. 
Pero quizá lo más notable, al menos desde nuestra perspectiva, sería el hecho de que Pausanias no advirtiera el vínculo entre este culto de Ártemis Lafria y el imperial en Patras, atestiguado explícitamente, por lo menos, en una notable inscripción (CIL III, 510) ${ }^{54}$. También se establecía allí una asociación entre este culto y el de Diana practicado por los veteranos romanos, acorde con la ubicación del santuario de la Lafria en la acrópolis de la ciudad, que hacía evidente algún tipo el vínculo con el fenómeno imperial romano asociado con lo capitolino. Pausanias pasa por alto, por lo tanto, la incidencia del fenómeno global del imperio sobre las experiencias cultuales de lo "local". Este procedimiento no es extraño, por ejemplo, si tenemos en cuenta que las estatuas de Zeus Olímpico, Atenea y Hera, que menciona el periegeta en el ágora de la ciudad (7.20.3), pueden ser en realidad parte de una interpretatio graeca del Capitolio de una colonia romana, que atenúa la presencia imperial, pero no logra silenciarla $^{55}$. Si pensamos en el imperio romano como un espacio de mediación cultural, en el que la movilidad no dejó jamás de estimular múltiples intercambios, en especial religiosos, en un marco de intensa conectividad entre tendencias globales y experiencias locales, ese culto "local" no puede dejar de estar atravesado por la realidad del imperio. En ese sentido, podría entenderse que lo que Pausanias observó en Patras era un ejemplo más de la dinámica de universalización de los cultos imperiales, sujeta al diálogo recíproco en un imperio culturalmente policéntrico ${ }^{56}$.

54. Rizakis, A.: Achaïe I. Sources textuelles et histoire régionale. A0ฑ́va, 1995, n. ${ }^{\circ} 5$.

55. Auffarth, Chr.: "Verräter - Übersetzer?: Pausanias, das römische Patrai und die Identität der Griechen in der Achaea", en CANCIK, H. y RüPKE, J. (eds.): Römische Reichsreligion und Provinzialreligion. Tübingen, 1997, p. 231. Incluso, uno puede suponer la relación entre el culto de Ártemis y las regulaciones conocidas sobre el ritual de Diana en el Aventino (ILS 4907; CIL 3.1933; GoldhilL: 2010, 64). A diferencia de otras colonias en Grecia, se ha observado que Patras guardó una mayor pureza formal, en lo lingüístico, y una mayor fidelidad al modelo romano quizá hasta el siglo III d. C.: RizAKIs, A.: "Le grec face au latin. Le paysage linguistique dans la peninsule balkanique sous l'empire", en Solin, H., Salomies, O. y Liertz, U. (eds.): Acta Colloquii Epigrafici Latini. Helsinski, 1995, p. 384 .

56. Esta idea se desprende del importantísimo aporte interpretativo del proyecto Römische Reichsreligion und Provinzialreligion dirigido por Jörg RüPKE. Ver: BONNET, C.: "L'empire et ses religions: Un regard actuel sur la polémique Cumont-Toutain concernant la diffusion des 'religions orientales', en CANCIK, H. y RüPKE, J. (eds.): Die Religion des Imperium Romanum. Tübingen, 2009, pp. 69-73. 


\section{LA IDENTIDAD DE LOS CORINTIOS: ¿GRIEGOS O ROMANOS?}

El libro II está dedicado a la Argólide y la Corintia, en la que destaca, desde luego, la visita a Corinto. Allí, en mi opinión, el periegeta experimenta un cierto conflicto con la perspectiva local sobre la identidad. La historia de esta ciudad había sufrido un quiebre decisivo como resultado de su destrucción a manos romanas en el 146 a. C., que no parece haberse limitado al núcleo urbano, sino que se extendió por Istmia, Céncreas y el Hereo de Peracora ${ }^{57}$. Algunos testimonios literarios, especialmente Cicerón, y también arqueológicos brindan indicios en favor de alguna continuidad en la ocupación del $\operatorname{sitio}^{58}$, pero la ciudad como comunidad política, como pólis, había cesado su existencia. El territorio, por su parte, quedó dividido en dos áreas. La primera fue incorporada al ager publicus Romanus, mientras que la segunda fue asignada a Sición, que junto con Argos recibió el honor de organizar los sucesivos Juegos Ístmicos. Un epigrama de Antípatro de Sidón (s. II a. C.) acentúa de forma muy plástica esta imagen de destrucción y abandono de Corinto: "Nada, en efecto; ni siquiera un rastro, desventurada, ha quedado de ti, lo devoró completamente la guerra tras arrebatarlo todo" "59.

Unos cien años más tarde, en el 44 a. C., Julio César promovió la refundación de la ciudad como colonia romana con el nombre de Colonia Laus Iulia Corinthiensis, a la cual pobló inicialmente con libertos romanos y veteranos (Str. 8.6.23; Plu., Caes. 57.8). Sin embargo, parece que la composición social del asentamiento varió mucho durante el siguiente siglo ${ }^{60}$. Durante el siglo II d. C., como advierte D. Engels, "Corinto alcanzó el apogeo de su tamaño y prosperidad ${ }^{61}$, y tanto el ordenamiento del paisaje urbano-rural, como el diseño espacial y arquitectónico de la nueva ciudad fueron propiamente romanos (foro, capitolio, centuriación y planificación urbana, red viaria, baños públicos, acueducto, etc. $)^{62}$.

57. FornIs, C.: "La construcción de la identidad romana en Corinto", Habis, 38, 2007, p. 206. La destrucción: 7.14.1-16.10; Pol. 38.9.1-18.12; 39.2-6; Str. 8.6.23; D.S. 32.26.1-5; Liv. Perioch. 52; Iust. 34.2.1-6; Flor. 1.32.4-7; Oros. 5.3; Zonar. 9.31.

58. Cic., Agr. 1.2.5; 2.19.51; Tusc. 3.53.

59. Anth. Pal. 9.151; Difabio, E.: «Un mapa de la nostalgia: ciudades otrora florecientes en el libro 9 de Antología Palatina", AFC, 28, 2015, pp. 11-12, de quien tomo la traducción del epigrama.

60. Spawforth, A.: "Roman Corinth: The Formation of a Colonial Élite", en Rizakis, A. D. (ed.): Roman Onomastic in the Greek East: Social and Political Aspects, Meletemata, 21, 1996, pp. 167-182.

61. Engels, D.: Roman Corinth: An Alternative Model for the Classical City. Chicago, 1990, p. 20.

62. FORNIS: 2007, 212-213. 
El impacto cultural (y político) romano fue, pues, muy grande. Algunos autores han señalado que Corinto era el centro de la romanidad en la provincia de Acaya ${ }^{63}$. Los indicios al respecto son notables. Los Corintios fueron famosos, por ejemplo, por su afición por las peleas de gladiadores y por la caza de bestias salvajes, considerada desmesurada por muchos griegos (D. Chr. 31.121). En una fecha tan tardía como la segunda mitad del siglo III d. C. se construyó un gran anfiteatro para alojar estas actividades $^{64}$. El testimonio de la Carta 198 del Pseudo Juliano de fines del siglo I d. C., o comienzos del II d. C., va en sintonía con esta crítica griega a prácticas culturales llevadas a cabo en la ciudad que no eran propias del helenismo $(408 \mathrm{~d}-409 \mathrm{a})^{65}$.

Pero hay señas, más allá del viraje de las inscripciones públicas del latín al griego tras Adriano ${ }^{66}$, que parecen apuntar a que a partir del siglo II d. C. la élite corintia se habría asociado activamente con el pasado helénico de su ciudad, como implican el elogio burlón de Favorino a su carácter helénico (D. Chr., 37.1; 26. Cfr. Arist., Or. 46) ${ }^{67}$, o un raro pasaje de la Fisiognomía de Antonio Polemón — conservado solo en árabe- en el que el orador mencionaba su interés específico por los griegos "puros", entre los que enumeraba a argivos, corintios y "los demás" "68.

Un indicio notable, sin embargo, de la actitud negativa de parte de Pausanias con respecto a esta tendencia es su indicación de la discontinuidad de los sacrificios anuales a Deima ("el Terror"):

(6) Yendo desde el ágora por otro camino que conduce a Sición se puede ver a la derecha del camino un templo y una imagen de bronce de Apolo, y un poco más allá una fuente llamada de Glauce, pues en ésta se lanzó Glauce, según dicen, pensando que el agua sería un remedio contra las pócimas de Medea. Más arriba de esta fuente está el llamado

63. Cartledge y Spawforth: 1989, 104; Alcock: 1993, 156, 166-169.

64. Patras, otra colonia romana, es el único otro ejemplo conocido en Grecia de una ciudad con anfiteatro: SPAWForth, A.: "Corinth, Argos, and the imperial cult. Pseudo-Julian, Letters 198", Hesperia, 63, 1994, p. 217. Sin embargo, esto puede tener que ver también con opciones completamente locales porque las peleas de gladiadores podían llevarse a cabo también en teatros.

65. KÖNIG, J.: "Favorinus' Corinthian Oration in its Corinthian context", PCPhS, 47, 2001, p. 152.

66. Existen 104 inscripciones anteriores a Adriano: 101 en latín y solo 3 en griego. 15 textos griegos y 10 latinos sobreviven del reinado de Adriano y, hasta Galieno, 24 textos griegos y 7 latinos: KenT, J. H.: Corinth. Results of Excavations Conducted by the American School of Classical Studies at Athens, vol. VIII (3) ("The Inscriptions 1926-1950"), 1966.

67. KÖNIG: 2001.

68. Spawforth: 2012, 254; Swain, S. (ed.): Seeing the Face, Seeing the Soul: Polemon's Physiognomy from Classical Antiquity to Medieval Islam. Oxford, 2007, p. 427. 
Odeón, y junto a él está el sepulcro de los hijos de Medea; sus nombres son Mérmero y Feres, y se dice que ellos fueron apedreados por los corintios a causa de los regalos que le llevaron a Glauce. (7) Como su muerte fue violenta e injusta, aniquilaba a los niños pequeños de los corintios, hasta que por vaticinio del dios se establecieron sacrificios anuales en su honor y se erigió una estatua de Deima. Ésta todavía existe entre nosotros; es la figura de una mujer que inspira terror.

Pero después de que Corinto fue destruida por los romanos y los antiguos corintios murieron, aquellos sacrificios ya no se celebraban entre los colonos, ni sus hijos cortan sus cabellos, ni llevan vestidos negros. (2.3.6-7).

Pausanias creía que los niños estaban, en efecto, enterrados en el lugar, aunque es probable que estuviera mal informado porque el templo de Hera Akraia, donde los niños supuestamente habían sido muertos y, luego, se habían vuelto objeto de culto cívico se encontraba a casi $65 \mathrm{~km}$ de distancia en Peracora ${ }^{69}$. La idea de un hiato físico entre los antiguos habitantes de la ciudad y los nuevos se completa con una alusión al quiebre definitivo en una práctica ritual específica de la comunidad cívica. Un sacrificio y una performance particular de duelo colectivo por un acontecimiento del pasado mítico habían desaparecido, tal como si los nuevos habitantes no se consideraran ya responsables de mitigar su culpa por la injusticia cometida contra los hijos de Medea. Sobre ese punto, la lectura de Pausanias busca poner el énfasis en la discontinuidad, lo que se advierte en diversos pasajes en los que elabora a contrapelo de la tradición local.

En primer lugar, el periegeta sugiere una discontinuidad biológica. En el pasaje citado arriba lo explicita: Corinto fue destruida y sus antiguos habitantes murieron (2.3.6). Destaca también una marcada distinción

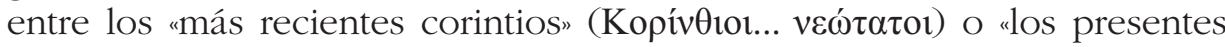

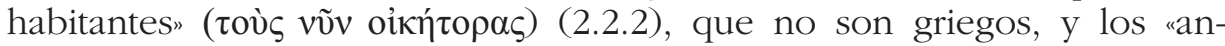

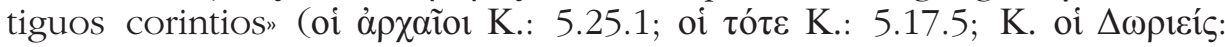
5.10.5), que lo habrían sido. Los nuevos colonos son considerados, entonces, como recién llegados sin vínculos con la antigua pólis: "En Corinto no vive ya ninguno de los antiguos corintios, sino colonos enviados por los romanos... Mumio, que estaba al mando del ejército romano, asoló

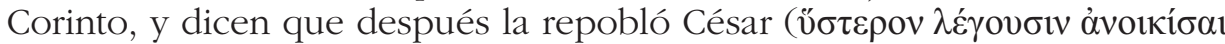

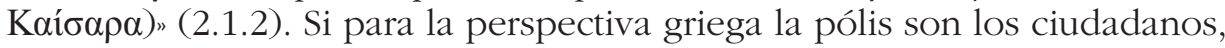

69. Dunn, F.: "Pausanias on the tomb of Medea's children", Mnemosyne, 48 (3), 1995, p. 349. Varias fuentes reportan la muerte de los hijos de Medea: DunN, F.: «Euripides and the Rites of Hera Akraia", GRBS, 35, 1994, pp. 105-108. 
la desaparición de estos últimos es sugerida en el texto como la extinción del fenómeno políada, que implicaba una ruptura decisiva entre la Corinto griega y la romana.

En segundo lugar, una discontinuidad en el asentamiento urbano, es decir, en los monumentos que la pólis ofrecía a la vista de sus visitantes foráneos. Se ha advertido que la Corinto que Pausanias visitó era muy pobre en el tipo de material que interesaba más al periegeta: obras de arte y monumentos previos a la conquista romana ${ }^{70}$. Es interesante que en 2.3.1, por ejemplo, escriba: "Por encima del ágora hay un templo de Octavia, hermana de Augusto, que fue emperador de los romanos después de César, el fundador de la Corinto actual ( Antes había expuesto lo siguiente: "Entre los monumentos dignos de mención en la ciudad hay unos que son vestigios del pasado, pero otros, la mayoría, fueron construidos en el esplendor posterior" (2.2.6). La ciudad tiene "esplendor", pero casi no exhibe huellas de un pasado griego que se supone desvanecido. En su materialidad es romana, impensable sin el dominio romano. ¿Queda sitio, entonces, para ser pensada como una ciudad griega?

Finalmente, en tercer lugar, Pausanias no deja de advertir la discontinuidad cultural. En efecto, lo había señalado en el caso del interrumpido sacrificio a Deima, pero lo advierte también en el caso de la lengua de los pobladores, al menos, de la lengua oficial en la que se inscribían las decisiones públicas propias del hábito epigráfico de una ciudad imperial romana: "Más arriba del teatro hay un santuario de Zeus Capitolino en lengua de los romanos; en lengua griega sería llamado Corifeo" (2.4.5). La Corinto actual no posee, por lo tanto, ni la lengua, ni los ritos de la antigua y, por lo tanto, difícilmente puede considerársela "griega", o parte del "helenismo", al menos, tal como el mismo es concebido por Pausanias.

\section{A MODO DE CIERRE: "GLOCALIDADES" GRIEGAS IMPERIALES}

Una vasta literatura académica ha resaltado la articulación existente entre procesos globales y locales en el mundo contemporáneo, lo que ha permitido advertir que la 'localidad' en sí misma es un producto específico

70. Las consecuencias del saqueo de Corinto para la cultura material: ArAFAT, K.: Pausanias' Greece. Ancient Artists and Roman Rulers. Cambridge, 2004, pp. 92-97.

71. Posiblemente el templum Gentis Iuliae: Torell, M.: "Pausania a Corinto. Un intellettuale greco del secondo secolo e la propaganda imperiale romana", en KNoEPFLer, D. y PIÉRART, M. (eds.): Éditer, traduire, commenter Pausanias en l'an 2000. Genève, 2001, p. 179. 
de la intersección de perspectivas supralocales en espacios más discretos ${ }^{72}$. No se trata de dos problemas diferentes, sino de una cuestión de escala de observación del objeto, que, según cómo se calibre, nos puede permitir advertir otro imperio romano en el siglo II d. C. Recientemente, el tema ha sido explorado para el mundo grecorromano con resultados alentadores ${ }^{73}$. En el caso de Pausanias, parece claro que dos fuerzas globales principales atravesaban el mundo que recorría y que intentaba conocer. Aunque el periegeta no necesariamente fuera consciente de ello, el mundo griego que recorrió, aparentemente conformado por comunidades de carácter marcadamente local, estaba inserto y atravesado profundamente por las realidades del diálogo y de la interacción a escala local del imperio romano y del panhelenismo.

El periegeta recorrió Grecia y escribió una obra para orientar a su lector sobre cómo volverse un theôrós, es decir, un correcto observador/ apreciador de la cultura griega ${ }^{74}$. Inserto en una tradición literaria, que puede remontarse por lo menos a Hecateo, Pausanias reconoció la dificultad de acceder al "helenismo" en estado puro, dado el carácter disputado de las tradiciones locales. Sin embargo, frente a esa polifonía propia de una distribución local del conocimiento buscó presentar una voz autorizada capaz de superar esa multiplicidad y brindar una visión de conjunto. Al hacerlo, reconoció su propia posición de forastero con una voz externa porque construyó narrativamente su relato como el de un viajero que cruzaba el Egeo para recorrer Grecia y demostrar que "interpretar los restos del pasado griego requiere mucho más que solo conocimiento local, ${ }^{75}$. Pero a la vez su voz también era interna porque como pepaideuménos, exponente, por su formación, del panhelenismo, se pensaba capaz de juzgar a partir de criterios estéticos y culturales de la época, que apreciaban el arcaísmo de las historias, de los vestigios materiales y de las costumbres de los lugares recorridos de una Grecia "libre" anterior a la conquista romana. Su mirada cultural "global" le permitía definir, entonces, qué era griego y qué no lo era, qué era antiguo y qué no, qué era o no era local/peculiar.

Se ha señalado repetidamente que Pausanias daba la espalda a la realidad del imperio romano. En efecto, rara vez se refiere a monumentos, esculturas o acontecimientos posteriores al 146 a. C., lo que alimentó cierta ilusión de acceso a través de su obra a un arcaísmo legítimo o al

72. Friedman, J.: Identidad cultural y proceso global. Madrid, 2001.

73. Whitmarsh, T. (ed.): Local Knowledge and Microidentities in the Imperial Greek World. Cambridge, 2010.

74. GoldhilL: 2010, 67.

75. KÖNIG: 2001, 157. 
tradicionalismo de los cultos, ritos, sacrificios, ofrendas descriptas. Pero como J. Friedman ha señalado, cuando abordamos "tradiciones" culturales estamos expuestos siempre a dos grandes riesgos: 1) caer en el enfoque de "invención de las tradiciones", que ve al tradicionalismo como algo "inauténtico", apartado del "pasado real" sin atender a los sentidos implicados para la identidad local; 2) abusar del enfoque de la hibridación/ criollización, entendido como "adulteración de la cultura", cuando resulta, desde todo punto de vista, imposible saber qué es la cultura en estado "puro" ${ }^{76}$. ¿Existía algo como Grecia en "estado puro", se podía delimitar en verdad un tó hellenikón, más allá de la imaginación cultural? No solo las nociones de helenismo han sido matizadas en la historiografía de los últimos años, sino también las de romanidad, puesto que justamente no existía nada como "un paquete cultural prefabricado" de cultura romana o griega a adoptar o evitar, sino variedades regionales que eran productos específicos de las tensiones en que cada localidad se estructuró dentro de un mundo progresivamente global e interconectado ${ }^{77}$.

Un abordaje más productivo de la experiencia de Pausanias con respecto a lo "local" no debe, por lo tanto, alimentar un debate dicotómico sobre la primacía de una agenda cultural panhelénica o del interés anticuario sesgado por la recolección de datos locales curiosos. Si logramos advertir que su viaje implicó entrar en contacto con memorias, identidades y prácticas cívicas y religiosas locales, que eran a la vez particulares, en tanto específicas de un lugar y percibidas como propias y distintivas por una comunidad reducida de personas y, al mismo tiempo, que eran globales en tanto manifestaciones concretas de los modos en que las diversas fuerzas mediterráneas (imperio, helenismo) incidían en las localidades de un mundo griego plenamente inserto en aquel espacio de intercambio cultural y de conectividad intensa, habremos avanzado mucho en la comprensión de la obra y de su periodo histórico.

En su visita a Tegea, Patras y Corinto, ciudades disímiles entre sí, con sus propias experiencias históricas y configuraciones político-culturales, Pausanias registró la intervención romana puntual en el reordenamiento del paisaje político-cultural griego $^{78}$. En ese sentido, son evidentes sus

76. FRIEDMAN: 2001, 32-33.

77. La expresión de "paquete cultural prefabricado" es de: Woolf, G.: Becoming Roman. The Origins of Provincial Civilization in Gaul. Cambridge, 2003 (1998), p. 11. Sin embargo, se ha vuelto ya un lugar común en la antropología la crítica a la reificación de la idea de cultura en estado puro.

78. Que son las acciones de un vencedor sobre el territorio dominado, como puede apreciarse en la excelente síntesis de: CoRTÉs Copete, J. M.: "Polis romana. Hacia un nuevo modelo para los griegos en el Imperio", SHHA, 23, 2005, pp. 413-436. 
menciones al despojo de los colmillos del jabalí de Calidón y de la estatua de marfil del templo de Alea Atenea, el despoblamiento de la propia Calidón en Etolia y el envío de la estatua y culto de Ártemis Lafria a Patras, o, finalmente, la destrucción de Corinto y su refundación como colonia romana. Cada una de estas realidades, lógicamente, hizo a Pausanias ver realidades locales, únicas, dentro del universo del helenismo. Sin embargo, en esta particularización de lo local, se escondía una integración más profunda a procesos político-culturales de escala global relacionados con el nuevo marco político del imperio.

En el caso de Tegea, la remoción de los colmillos no condujo al periegeta a preguntarse sobre el sentido de las demás ofrendas expuestas. Dado su dominio de la obra de Heródoto, y su conocimiento de la rivalidad contemporánea entre espartanos y tegeatas, podría haber inferido que la exposición de los grilletes guardaba una relación específica con la explotación romana global del tópico de la virtus militar espartana. En ese caso, los fenómenos globales del imperio y del helenismo se articulaban de forma inextricable en un santuario peloponesio, cuyas ofrendas revelan cómo la memoria local de los tegeatas estaba atravesada y moldeada en relación y diálogo tenso con los fenómenos globales frente a los que construía su identidad comunitaria.

En el caso del peculiar sacrificio ofrecido a Ártemis Lafria en Patras, Pausanias lo reconoce como un resultado de la intervención romana. Patras estaba casi deshabitada, y había sido revitalizada con su conversión en colonia romana, lo que motivó la llegada de una diosa con un nombre "extranjero", una estatua "traída de otro lugar" y un sacrificio anómalo o

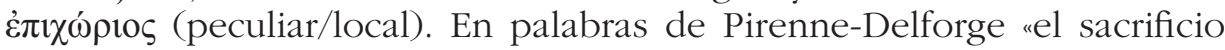
en Patras es al mismo tiempo 'local' y 'peculiar', que significa diferente de una regla 'estándar'”79. La supuesta regla estándar es griega, pero su peculiaridad también puede derivarse de un diálogo cultural activo con prácticas religiosas romanas, como muestra su parecido con el culto de Diana en el Aventino. Pausanias había brindado elementos para establecer esta relación, pero, en el momento de explicar el sacrificio, dejó de lado la conexión romana y optó, por el contrario, por interpretarlo como un culto etolio tradicional trasladado a Acaya. Si miramos más atentamente, podemos ver que, en una colonia romana, que había recibido población aquea y un contingente de veteranos romanos, helenismo e imperio se yuxtaponían creando una localidad particular, pero que era producto de la inserción dinámica de la comunidad y sus prácticas dentro del imperio.

79. Pirenne-Delforge: 2006, 117. 
Finalmente, la visita de Pausanias a Corinto adopta un tono más polémico, en el que es explícita la incidencia del fenómeno global imperial. La conquista romana, en efecto, es la causa de la eliminación del helenismo en esa comunidad y de la creación de una localidad nueva. Además, es posible que la visita del periegeta coincidiera con un momento de redefinición de la identidad corintia, cuando se intentaba establecer un vínculo con las tendencias globales del helenismo de la época, apelando al pedigrí griego de la ciudad. Sin embargo, Pausanias busca cancelar esta posibilidad aludiendo a una ruptura radical entre antiguos y nuevos pobladores. Lo local, en este caso, sería para Pausanias el carácter plenamente romano de Corinto, lo que implica una lectura esencialista de la identidad, que no se condice con el predominio desde época helenística de las ideas de autoadscripción cultural al helenismo.

Como conclusión, podemos señalar que el marco de referencia desde el cual Pausanias visita/conoce lo local es el helenismo como un fenómeno cultural global del Mediterráneo oriental. Sin embargo, los espacios que visita y menciona aparecen en el momento de su descripción como localidades atravesadas inevitablemente por el fenómeno global del imperio (como también lo está el propio Pausanias como sujeto). El proyecto de la Periégesis puede ser interpretado como total. El interés marcado, en efecto, por los pánta tà Hellenikà, por todas las cosas griegas, se construye en la obra a partir de un "helenismo" estándar, que en la práctica concreta es ficticio, e insertando las tradiciones 'locales' que dan forma al mismo a partir de sus particularidades. Su apelación a construir una memoria de Grecia anclada en lo antiguo, en el pasado, en lo tradicional, no puede, aunque el autor lo pretenda, escindir la realidad imperial romana porque esta ha modificado lo 'local' hasta tal punto que su viaje, después de todo, se ha convertido en una invitación no a visitar Grecia, sino la provincia romana de Acaya y sus localidades. No es extraño, un viaje por un paisaje homogéneo y monótono atraería a muy pocos viajeros.

\section{REFERENCIAS BIBLIOGRÁFICAS}

Agallopou, P.: "Two unpublished Coins from Patrae and the Name of the Roman Colony", Hesperia, 18 (4), 1989.

AkUjÄRvI, J.: Researcher, Traveller, Narrator: Studies in Pausanias' Periegesis. Lund, 2005.

Alcock, S.: Graecia Capta. The Landscapes of Roman Greece. Cambridge, 1993. 
Antela Bernárdez, B.: "El paisaje urbano de Atenas, entre memoria de guerra e identidad colectiva", en Vidal, J., Antela, B. y Sierra Martín, C. (eds.): Memoria del Conflicto en la Antigüedad. Zaragoza, 2017.

Arafat, K.: Pausanias' Greece. Ancient Artists and Roman Rulers. Cambridge, 2004.

Auffarth, Chr.: "Verräter - Übersetzer?: Pausanias, das römische Patrai und die Identität der Griechen in der Achaea", en CANCIK, H. y RüPKE, J. (eds.): Römische Reichsreligion und Provinzialreligion. Tübingen, 1997.

Bonnet, C.: "L'empire et ses religions: Un regard actuel sur la polémique Cumont-Toutain concernant la diffusion des 'religions orientales'", en CANCIK, H. y RÜPKe, J. (eds.): Die Religion des Imperium Romanum. Tübingen, 2009.

Bowersock, G.: Hellenism in Late Antiquity. Cambridge, 1990.

BURKERT, W.: Greek Religion. Cambridge (Ma.), 1985.

Cartledge, P. y Spawforth, A.: Hellenistic and Roman Sparta: A Tale of Two Cities: London, 2002.

Cortés Copete, J. M.: "Polis romana. Hacia un nuevo modelo para los griegos en el Imperio", SHHA, 23, 2005, pp. 413-436.

Difabio, E.: "Un mapa de la nostalgia: ciudades otrora florecientes en el libro 9 de Antología Palatina", AFC, 28, 2015.

Dorati, M.: "Pausania e il modello erodoteo: le tradizioni di Fliunte", en Giangiulio, M. (ed.): Erodoto e il 'modello erodoteo'. Formazione e trasmissione delle tradizioni storiche in Grecia. Trento, 2005, pp. 315348.

Dunn, F.: "Euripides and the Rites of Hera Akraia", GRBS, 35, 1994

DunN, F.: "Pausanias on the tomb of Medea's children", Mnemosyne, 48 (3), 1995.

Engels, D.: Roman Corinth: An Alternative Model for the Classical City. Chicago, 1990.

ERBSE, H.: Studien zum Verständnis Herodots. Berlin-New York, 1992.

ForNIS, C.: "La construcción de la identidad romana en Corinto", Habis, 38, 2007.

Fornis, C.: Esparta. La historia, el cosmos y la leyenda de los antiguos espartanos. Sevilla, 2016.

Fougères, G.: Mantinée et l'Arcadie orientale. Paris, 1898.

FRIEDMAN, J.: Identidad cultural y proceso global. Madrid, 2001.

Gengler, O.: "De qui est la mémoire? Construction identitaire et image du passé dans les sanctuaires du sud du Péloponnèse sous le hautempire", en Gangloff, A. (ed.): Lieux de mémoire en Orient grec à l'époque impériale. Berna, 2013, 179-198. 
Giangiulio, M.: "Constructing the Past: Colonial Traditions and the Writing of History: The Case of Cyrene", en Luraghi, N. (ed.): The Historian's Craft in the Age of Herodotus. Oxford, 2007 (2001).

Goldhill, S.: "What is local identity? The politics of cultural mapping?", en Whitmarsh, T. (ed.): Local Knowledge and Microidentities in the Imperial Greek World. Cambridge, 2010, pp. 46-68.

Навіснт, Ch.: Pausanias' Guide to Ancient Greece. Berkeley, 1985.

Hall, J.: Hellenicity. Between Ethnicity and Culture. Chicago, 2005 (2002).

Hejnic, J.: Pausanias the Perieget and the Archaic History of Arcadia. Praha, 1961, p. 83.

Herrero Ingelmo, M. C.: Pausanias. Descripción de Grecia, libros I-X, vol. I-III. Madrid, 1993.

Horden, P. y Purcell, N.: The Corrupting Sea. A Study of Mediterranean History. Oxford, 2000.

HutTon, W.: Describing Greece. Landscape and Literature in the Periegesis of Pausanias. Cambridge, 2005.

IMMERWAHR, W.: Die Lakonika des Pausanias auf ibre Quellen untersucht. Berlin, 1889.

Jennings, J.: Globalizations and the Ancient World. Cambridge, 2011.

Jones, Ch.: "Multiple Identities in the Age of the Second Sophistic", en Borg, B. E. (ed.): Paideia: The World of the Second Sophistic. Berlin, 2004, pp. 13-21.

Jost, M.: "Unité et diversité: la Grèce de Pausanias", REG, 119, 2006.

Jost, M.: Sanctuaires et cultes d'Arcadie. Paris, 1985.

Kent, J. H.: Corinth. Results of Excavations Conducted by the American School of Classical Studies at Athens, vol. VIII (3) ("The Inscriptions 1926-1950"), 1966.

KÖNIG, J.: "Favorinus' Corinthian Oration in its Corinthian context", PCPhS, 47, 2001.

Levi, C.: Cristo se detuvo en Éboli. Madrid, 2010 (1936).

Luraghi, N.: "Local Knowledge in Herodotus' Histories", en Luraghi, N. (ed.): The Historian's Craft in the Age of Herodotus. Oxford, 2007 (2001).

Meadows, A.: "Pausanias and the Classical Historiography of Classical Sparta", CQ, 45 (1), 1995.

Muñiz Grijalvo, E.: "La versión griega de la religión cívica como factor de integración en la ecúmene romana", SHHA, 26, 2008.

Musti, D., Maddoli y Moggi, M.: Pausania. Guida della Grecia, libros I-X. Milano, 1982-2012. 
PIÉRART, M.: "Panthéon et hellénisation dans la colonie romaine de Corinth: la 'redécouverte' du culte de Palaimon à l'Isthme", Kernos, 11, 1998, pp. 85-109.

Pirenne-Delforge, V.: "Ritual Dynamics in Pausanias: The Laphria", Kernos, suppl. 16, 2006.

Pretzler, M.: Pausanias: Travel Writing in Ancient Greece. London, 2007.

RIZAKIS, A.: "Le grec face au latin. Le paysage linguistique dans la peninsule balkanique sous l'empire", en Solin, H., Salomies, O. y Liertz, U. (eds.): Acta Colloquii Epigrafici Latini. Helsinski, 1995.

RIzAKIs, A.: Achaïe I. Sources textuelles et histoire régionale. A0ท́va, 1995.

Rizakis, A.: Achaïe II. La cité de Patras. Épigraphie et histoire. A日ńva, 1998.

RoBert, C.: Pausanias als Schriftsteller. Studien und Beobachtungen. Berlin, 1909.

ROBERTSOn, R.: Globalization. Social Theory and Global Culture. London, 1992.

RufER, M., "Paisaje, ruina y nación. Memoria local e historia nacional desde narrativas comunitarias en Coahuila", Cuiculco, 21 (61), 2015, 103-136.

SACKS, K.: Diodorus Siculus and the First Century. Princeton, 1990.

Spawforth, A.: "Corinth, Argos, and the imperial cult. Pseudo-Julian, Letters 198", Hesperia, 63, 1994.

Spawforth, A.: "Roman Corinth: The Formation of a Colonial Élite", en Rizakis, A. D. (ed.): Roman Onomastic in the Greek East: Social and Political Aspects, Meletemata, 21, 1996, pp. 167-182.

Spawforth, A.: Greece and Augustan Cultural Revolution. Cambridge, 2012.

Swain, S. (ed.): Seeing the Face, Seeing the Soul: Polemon's Physiognomy from Classical Antiquity to Medieval Islam. Oxford, 2007.

Torelu, M.: "Pausania a Corinto. Un intellettuale greco del secondo secolo e la propaganda imperiale romana", en KNoepfler, D. y Piérart, M. (eds.): Éditer, traduire, commenter Pausanias en l'an 2000. Genève: 2001.

Tsiolis, V.: "Santuarios de Arcadia y dominio romano", en CorTés COPETE, J. M., Muñiz Grijalvo, E. y Gordillo Hervás, R. (coords.): Grecia ante los imperios, V Reunión de historiadores del mundo griego. Sevilla, 2011.

Tuan, Y. F.: Topofilia. Un estudio de las actitudes, percepciones y valores sobre el entorno. Barcelona, 2007 (1974).

Vega Rodríguez, H. A.: La Biblioteca Histórica de Diodoro de Sicilia. Universalidad, escritura de la historia y el retrato de los cartagineses. Trabajo Final de Máster, Máster del Mediterráneo Antiguo UOC-UABUAH, Barcelona, 2017. 
Versluys, M.: "Roman Visual Material Culture as Globalising Koine", en PitTs, M. y Versluys, M. (eds.): Globalisation and the Roman World. World History, Connectivity and Material Culture. Cambridge, 2015.

WhitMarsh, T. (ed.): Local Knowledge and Microidentities in the Imperial Greek World. Cambridge, 2010.

Woolf, G.: "Becoming Roman, staying Greek: Culture, identity and the civilizing process in the Roman East", PCPhS, 40, 1994, pp. 116-143.

Woolf, G.: Becoming Roman. The Origins of Provincial Civilization in Gaul. Cambridge, 2003. 
